Original Article

\title{
VARIATIONS OF RENAL ARTERY: A CADAVERIC STUDY
}

\author{
Yogendra Singh", GL Shah"*, Ram Ji ${ }^{\star}$ \\ *Department of Anatomy, BRD Medical College, Gorakhpur, UP. \\ ${ }^{* \star}$ Department of Anatomy, Institute of Medical Sciences, Banaras Hindu University Varanasi, UP.
}

\begin{abstract}
Introduction: Renal arteries are the lateral branches of abdominal aorta, which vary in number, origin and course. The aim of this study was to document the incidence of renal artery variations in number and position, which can be advantageous to urosurgeons and imaging experts.
\end{abstract}

Material \& Methods: The study was conducted on 36 formalin fixed embalmed cadavers. The renal artery variations were observed and noted during routine posterior abdominal wall dissection for medical undergraduates in dissection hall in the Department of Anatomy, BRD Medical College Gorakhpur and IMS, BHU Varanasi.

Results: We observed accessory renal artery (ies) in $30.56 \%$ of cases with unilateral incidence in $27.78 \%$ and bilateral in $2.67 \%$ cases. Accessory hilar renal artery (ies) were observed in $16.68 \%$ and accessory polar renal artery (ies) in $13.89 \%$ cases. Accessory arteries were more common on left $(16.68 \%)$ than on the right side $(11.12 \%)$. Inferior polar arteries were more common than superior polar arteries.

Conclusion: Knowledge of the variations of renal artery is of immense importance to the urosurgeons during renal transplantation, partial nephrectomy, laparoscopic surgery and angiographic interpretation by radiologists.

Keywords: Embalmed cadaver, accessory hilar renal artery, accessory polar renal artery.

\section{INTRODUCTION}

The kidney is a retroperitoneal organ, usually supplied by single renal artery, which is a lateral branch of abdominal aorta below the origin of superior mesenteric artery. Usually one renal artery supplies each kidney and one renal vein drains the kidney. Normally, renal artery enters into the kidney through the hilum and divides into five segmental branches. Graves (1954) gave the first detailed account of the primary pattern of renal vascular segmentation[1]. Accessory renal artery is an addition to normal single renal artery. It is called accessory hilar renal artery if it enters through the hilum in addition to the normal single renal artery and called accessory polar renal artery if entering the respective kidney through the sites other than the hilum, usually near the pole. These accessory renal arteries commonly arise from the abdominal aorta inferior to the normal level of origin of renal artery but it may also arise from the phrenic, superior mesenteric, inferior mesenteric and common iliac artery. The variations of renal artery are common in their number, positions and course[2,3]. The presence of an accessory renal artery was reported in approximately $30 \%$ of cases by many researchers[4-6] and this presence of accessory renal arteries is found associated with high failure rate and post-operative complications in renal transplantation[5]. There is a high incidence of urinary tract obstruction due to the accessory renal arteries running anterior or posterior to uretro-pelvic junction leading to hydronephrosis[7]. It is important to be aware that accessory renal arteries act as end arteries; therefore, if an accessory renal artery is ligated in the donor kidney and not vascularized subsequently, the part of the kidney

\section{Address for Correspondence:}

Dr. Yogendra Singh, Assistant Professor, Department of Anatomy, BRD Medical College, Gorakhpur-273013, UP. Mob: 09450979094 Email: yogisingh99@gmail.com 
Variations of renal artery......

supplied by it is likely to become ischemic[4].

Thus a detailed knowledge of variations of renal artery is helpful in preventing the failure and complications in renal vascular surgery, partial nephrectomy and misinterpretation of angiography by radiologists.

\section{MATERIAL AND METHODS}

The study was conducted in thirty six (36) formalin fixed embalmed cadavers during routine posterior abdominal wall dissection for teaching of medical undergraduates in the Department of Anatomy, BRD Medical College, Gorakhpur and Institute of Medical Sciences, BHU, Varanasi, Uttar Pradesh, India. Out of 36 cadavers, 31 were male and 5 were female. The renal area was explored upto the pelvis and the findings were noted regarding the variations of renal artery in their number, origin and course in both right and left kidney.

\section{OBSERVATIONS AND RESULTS}

The accessory renal arteries were observed in $30.56 \%$ $(11 / 36)$ cases and out of these, $16.68 \%$ were accessory hilar renal arteries entering into kidney through the hilum and $13.89 \%$ accessory polar renal arteries entering into the kidney at sites other than the hilum i.e. at or near the respective poles. All sites of entry of accessory polar arteries were found on the anterior surface of the respective kidney. Double hilar arteries were reported in $11.12 \%$ cases of which $5.56 \%$ on right and $2.78 \%$ on left side and bilateral in $2.78 \%$ cases. Triple hilar arteries were reported in $5.56 \%$ cases on the left side only. Accessory superior polar artery was reported in $5.56 \%$ cases and inferior polar artery in $8.33 \%$ cases. Unilateral renal artery variations was reported in $27.78 \%$ and bilateral in $2.67 \%$ cases (Table 1, Fig. 1-4). Out of 5 females, only in one female $(20 \%)$ double hilar renal artery was noted and that too on the right side.

Table 1: Incidence of accessory renal artery in present study (Out of 36 cases)

\begin{tabular}{|l|c|c|c|c|}
\hline Renal artery & Right & Left & B/L & Total \\
\hline Single hilar artery (Normal) & $32 / 36(88.89 \%)$ & $30 / 36(83.33 \%)$ & $35 / 36(97.22 \%)$ & $25 / 36(69.44 \%)$ \\
\hline Accessory double hilar arteries & $2 / 36(5.56 \%)$ & $1 / 36(2.78 \%)$ & $1 / 36(2.78 \%)$ & $4 / 36(11.12 \%)$ \\
\hline Accessory triple hilar arteries & $0 / 36(0 \%)$ & $2 / 36(5.56 \%)$ & $0 / 36(0 \%)$ & $2 / 36(5.56 \%)$ \\
\hline Accessory SPA & $1 / 36(2.78 \%)$ & $1 / 36(2.78 \%)$ & $0 / 36(0 \%)$ & $2 / 36(5.56 \%)$ \\
\hline Accessory IPA & $1 / 36(2.78 \%)$ & $2 / 36(5.56 \%)$ & $0 / 36(0 \%)$ & $3 / 36(8.33 \%)$ \\
\hline
\end{tabular}

SPA-superior polar artery, IPA- inferior polar artery

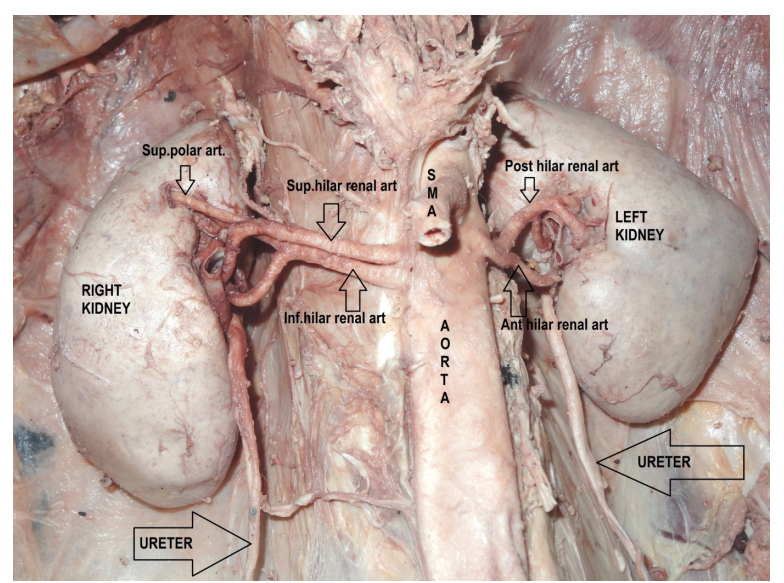

Fig. 1: Photograph showing bilateral double hilar renal arteries and inferior hilar renal artery giving a branch to superior pole of right kidney known as accessory superior polar artery (SMAsuperior mesenteric artery)

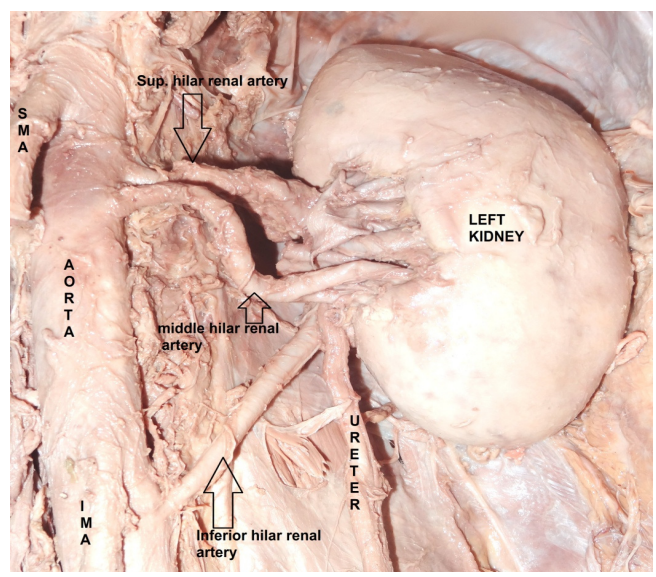

Fig. 2: Photograph showing triple hilar renal artery on left side, inferior hilar renal artery arising below the origin of inferior mesenteric artery (SMA-superior mesenteric artery, IMAinferior mesenteric artery) 


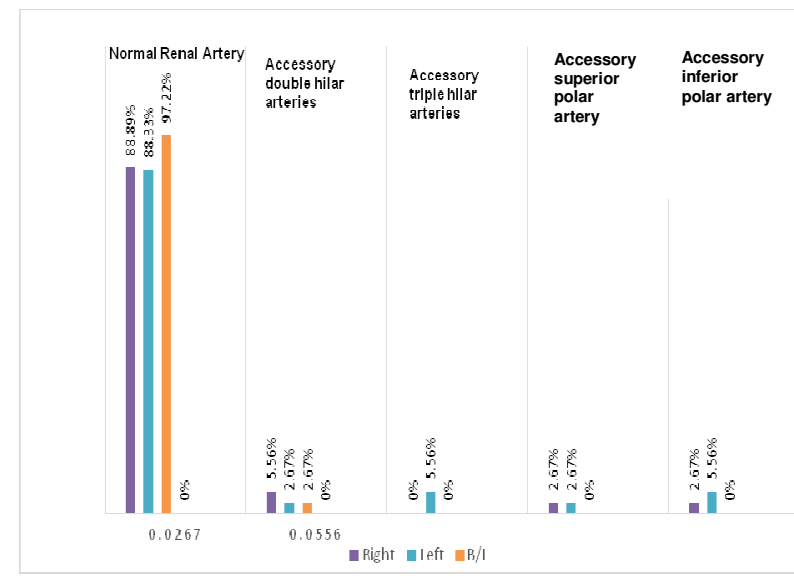

Fig. 3: Incidence of renal artery on right and left side

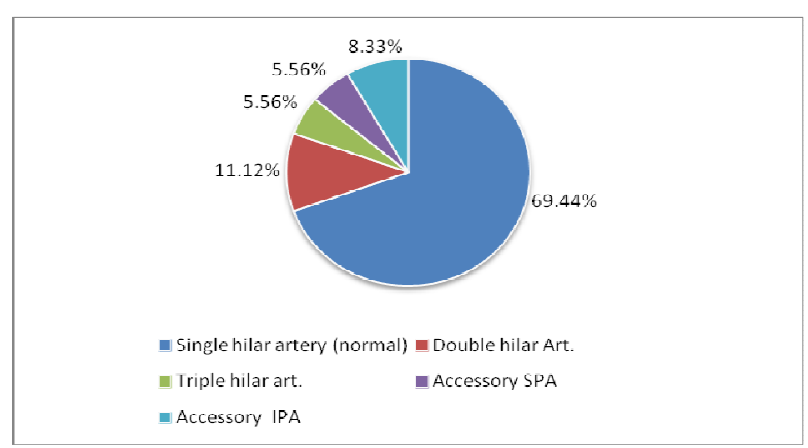

Fig. 4: Pie diagram showing incidence of renal artery on right and left side

\section{DISCUSSION}

Embryological explanation of these variations has been presented and discussed by Felix (1912) in an $18 \mathrm{~mm}$ fetus [8]. The developing mesonephros, metanephros, suprarenal glands and gonads are supplied by nine pairs of lateral mesonephric arteries arising from the dorsal aorta. Felix divided these arteries into three groups. The $1^{\text {st }}$ and $2^{\text {nd }}$ arteries as the cranial, the $3^{\text {rd }}$ to $5^{\text {th }}$ arteries as the middle, and the $6^{\text {th }}$ to $9^{\text {th }}$ arteries as the caudal group. The middle group gives rise to the renal arteries. Persistence of more than one artery of the middle group results as multiple renal arteries. Initially the metanephric kidney lies in the sacral region and subsequently with the differential growth of the abdominal wall, it ascends via the iliac fossa to its final destination in the lumbar region. The caudal arteries degenerate and one of the more proximal vessels which are closer to the final position of the kidney persist as a single renal artery on either side [9].

The failure of regression of these arteries result in accessory renal arteries. Thus, the multiple renal arteries in our study may be a result of persisting lateral mesonephric arteries from the middle group.

The various types of accessory renal arteries, their number, position and the way of entry into the kidney and its segmentation were studied extensively [2]. Bordei et al. (2004) reported 54 cases of double renal artery supplying one kidney. Out of 54 cases, 6 cases were bilateral [10]. There are reports of additional renal arteries in literature [11-13]. In our study we have observed double renal artery in $11.12 \%(3 / 36)$ cases, of which only one $(2.78 \%)$ was bilateral.

Extra hilar artery (ies) originating from hilar renal artery (ies), have vertical trajectory in comparison to polar arteries taking origin from the aorta and this vertical trajectory can lead to polar infarction [14]. Accessory arteries to the inferior pole, running anterior to the renal pelvis or ureter may be the cause of hydronephrosis due to the obstruction to the flow of urine at pelvic-ureteric junction or the proximal part of the ureter. Reported incidence of inferior polar arteries is $15.1 \%$ and that of superior polar arteries $9.6 \%$ cases [15-17]. Kumar and Prabha (2016) observed superior polar arteries in $13.09 \%$ and inferior polar in $5.95 \%$ cases in South Indian population [18]. In our study, accessory inferior polar artery were present in $8.33 \%$ cases and superior polar artery in $5.56 \%$ cases.

Brannen et al. (1982) and Gupta et al. (2010) were in opinion that, presence of multiple renal arteries have chances of rejection and poor graft functions $[19,20]$ but Benedetti et al.(1995) didn't find significant difference with regard to acute rejection rate in grafts with single or multiple arteries [21]. However, allografts with multiple renal arteries have risk of renal artery stenosis [22]. In renal transplantation, polar vessels can increase the failure rate due to thrombosis of renal vessels and urinary leakage [23]. It is important to be aware that the accessory renal arteries act as an end artery and if ligated, the part of kidney supplied by it is likely to become ischemic [4]. The presence of bilateral accessory renal arteries makes it technically difficult to procure the donor kidney for transplantation and also they result in increased incidence of subsequent complications.

The incidence of bilateral accessory renal arteries have been ranging from $1.66 \%$ to $10 \%$. Studies of Dhar and Lal (2005), reported bilateral accessory renal 
arteries in $5 \%$ cases [24] while in our study we noted them in $2.67 \%$ cases. Pollak et al. (1986), reported triple renal arteries in $4 \%$ and quadruple in $1 \%$ cases [25]. In our study, triple renal arteries were present in $5.56 \%$ cases and that too on left side.

Different studies showed that left side shows more variations than right [24-26]. In our study also, the left side renal artery variations were more common which is in concordance with the previous studies [24-16]. Saldarriaga et al. (2008) found no difference on left and right side [27].

\section{CONCLUSION}

The incidence of accessory renal artery are very high and more common on left side in number as well as in position. If an accessory artery cut or ligated, it will lead to damage of the respective segment of the kidney supplied by it. Thus a urosurgeon needs to be aware of the detailed knowledge of the variations of renal artery of the donor as well as of the recipient during renal transplantation. Knowledge of aforesaid variations does appear mandatory during nephrectomy, laparoscopic surgery and angiographic interpretations by radiologists.

\section{REFERENCES}

1. Graves FT. The anatomy of the intrarenal arteries and its application to segmental resection of the kidney. Brit J Surg. 1954; 42:132-139.

2. Sykes $D$. The arterial supply of the human kidney with special reference to accessory arteries. Brit J Surg. 1963; 50: 368-374.

3. Anson BJ, Daseler EH. Common variations in renal anatomy affecting blood supply, form and topography. Sur Gyn Obstet. 1961;112:439-449.

4. Satyapal KS, Haffejee AA, Singh B, Rasmsaroop L, Robbs J V, Kalideen JM. Additional renal arteries: Incidence and morphometry. Surg Radiol Anat. 2001; 23: 33-48.

5. Bergman RA, Afifi AK, Miyauchi R. Illustrated encyclopedia of human anatomic variations: Opus II Cardiovascular System: Arteries: Abdomen: Renal and Gonadal Arteries.

6. Vasbinder GB, Nelemans PJ, Kessels AG, Kroon AA, Maki JH, Leiner T, Beek FJ, Korst MB, Flobbe K, de Haan MW, van Zwam WH, Postma CT, Hunink MG, de Leeuw PW, van Engelshoven JM. Renal artery diagnostic imaging study in hypertension (RADISH) study group: Accuracy of computed tomographic angiography and magnetic resonance angiography for diagnosing renal artery stenosis. Ann Intern Med. 2004;141: 674-682.

7. Rao M, Bhat SM, Venkataramana V, Deepthinath R, Bolla SR. Bilateral prehilar multiple branching of renal arteries: a case report and literature review. Kathmandu Univ Med J. 2006;4:345-348.

8. Felix W. Mesonephric arteries (aa. mesonephrica). In Keibel F and Mall FP (Eds.). Manual of Human Embryology. $2^{\text {nd }}$ ed. Philadelphia: Lippincott, 1912. vol. 22, pp 820-825.

9. Bremer JL. The origin of the renal arteries in mammals and its anomalies. Am J Anat. 1915;18:179-200.

10. Bordei $P$, Sapte $E$ and lliesc D. Double renal artery originating from aorta. Surg Radiol Anat. 2004;26 (6): 474-479.

11. Krishnasamy N, Rao M, Somayaji SN, Koshy S, Rodrigues V. An unusual case of unilateral additional right renal artery and vein. International Journal of Anatomical Variations. 2010; 3: 911.

12. Ilke, AG, Aysin K, Ozcan G, Bulent B, Ahmet U, Mahul EK, Zafer ARI. Bilateral variations of renal and testicular arteries. International Journal of Anatomical Variations. 2009; 2: 45-47.

13. Patasi B and Boozary A. A case report: accessory right renal artery. International journal of Anatomical variations. 2009; 2:119-121.

14. Beyer RW and Daily PO. Renal artery dissection associated with GZ acceleration. Aviation, Space and Environmental Medicine. 2004; 75 (3): 284-287.

15. Pick JW, Anson BJ. The renal vascular pedicle. An anatomical study of 430 body halves. J Urol. 1940; 44:411-434.

16. Shoja MM, Tubbs RS, Shakeri A, Ardalan MR, Ardabili BR, Ghabili K. Asymptomatic bilateral ureteropelvic junction obstruction due to supernumerary renal arteries. Saudi Journal of Kidney Disease and Transplantation. 2008b; 9 (5): 806-808.

17. Weld KJ, Bhayani SB, Belani J, Ames CD, Harubi G, Landman $J$. Extrarenal vascular anatomy of kidney: assessment of variations and their relevance to partial nephrectomy. Urology. 2005; 66:985-989.

18. Kumar U, Prabha R. Study of prehilar branching pattern of renal artery in human cadaveric kidneys. Nat J Clin Anat. 2016; 5(2):86-90.

19. Brannen GE, Bush WH, Correa RJ, Gibbons RP, Cumes DM. Microvascular management of multiple renal arteries in transplantation. The Journal of Urology. 1982; 128 (1): 112115.

20. Gupta V, Kotgiwar S, Trivedi S, Deopujari R, Singh V. Bilateral variation in renal vasculature. International journal of Anatomical variations. 2010; 3: 53-55.

21. Benedetti E, Troppmann C, Gillingham K, Sutherland DE, Payne WD, Dunn DL, Matas AJ, Najarian JS, Grussner RW. Short and long term outcomes of kidney transplants with multiple renal arteries. Annals of Surgery. 1995; 221 (4): 406414.

22. Kamali K, Abbasi MA, Ani A, Zargar MA, Shahrokh H. Renal transplantation in allografts with multiple versus single renal arteries. Saudi Journal of Kidney Disease and Transplantation. 2012; 23 (2): 246-250.

23. Bayazit M, Gol MK, Zorhutuna Y, Tasdemir O, Bayazit K. Bilateral triple renal arteries in a patient with iliac artery occlusion: a case report. Surg Radiol Anat. 1992; 14:81-83. 
24. Dhar P, Lal K. Main and accessory renal arteries - a morphological study. Int J Anat Embryol. 2005; 110(2):101110.

25. Pollak R, Prussak BF, Mozes MF. Anatomic abnormalities of cadaver kidneys procured for purposes of transplantation. Am Surg. 1986; 52:233-235.
26. Patil UD, Ragavan A, Nadaraj, Murthy K, Shanker R, Helical CT. angiography in evaluation of live kidney donors. Nephrol Dial Transplant. 2001;16: 1900-1904.

27. Saldarriaga B, Perez AF, Ballesteros LE. A direct anatomical study of additional renal arteries in a colombian mestizo population. Folia Morphol. 2008; 67 (2):129-134. 